\title{
Need to increase awareness among family doctors and medical specialists of rickettsioses as an import disease in non-endemic areas
}

\author{
Y.A. Nur ${ }^{\mathrm{a}}$, A. Brandenburg ${ }^{\mathrm{a}}$, H.G.M. Niesters ${ }^{\mathrm{a}}$, J.A. Wagenaar ${ }^{\mathrm{b}}$, \\ A.D.M.E. Osterhaus ${ }^{a}$, J. Groen ${ }^{a}, *$ \\ 'Laboratory of Exotic Viral Infections, Department of Virology, Erasmus Medical Center Rotterdam, Dr Molewaterplein 40, \\ 3015 GD Rotterdam, The Netherlands \\ ${ }^{\mathrm{b}}$ Veterinary Microbiological Diagnostic Center, Faculty of Veterinary Medicine, Utrecht, The Netherlands
}

Received 24 August 1999; received in revised form 6 January 2000; accepted 18 January 2000

\begin{abstract}
Europeans travelling to (sub)-tropical countries have an increased risk for infections with Rickettsia. As serious consequences are associated with delay in specific antibiotic therapy, unequivocal diagnosis of this condition is needed. We focus here on the benefits of early, and consequences of late laboratory diagnosis, and emphasise the need of an increased awareness of rickettsioses among family doctors, as well as medical specialists, in non-endemic areas when evaluating patients with travel associated fever. (C) 2000 Elsevier Science B.V. All rights reserved.
\end{abstract}

Keywords: Rickettsia; Typhus; Imported disease

\section{Introduction}

Rickettsioses are associated with a significant morbidity and mortality in both tropical and subtropical countries and in several other parts of the world [1]. Vector borne diseases are considered rare in most of the West European countries. Today, an increasing number of vector-borne diseases like rickettsioses, has been noticed in many European countries [2-5]. This is mainly due to the fact that many Europeans are travelling more frequently to

\footnotetext{
*Corresponding author. Tel.: + 31-10-463-3431; fax: + 31-10463-3441.

E-mail address: groen@viro.azr.nl (J. Groen)
}

tropical areas [6,7]. In The Netherlands, the majority of these cases have been diagnosed in patients with a history of recent travel to those areas, and in one incident the etiological agent was introduced into the country by a travelling dog $[8,9]$. Serological screening for rickettsial diseases is rarely performed, as physicians do not include the possibility of rickettsioses in their differential diagnosis when evaluating patients with travel associated fever. In a retrospective serological screening carried out in our clinic among 54 travellers suspected for malaria, IgM and IgG antibodies against rickettsial antibodies were demonstrated in five patients, indicating that rickettsial infections may be more frequent among these patients. In none of these patients specific rickettsia 
diagnostics was requested [Groen and Nur, unpublished observation 1999]. Concerns are raised about problems of correct identification of cases of rickettsioses. Benefits of early, and consequences of late laboratory diagnosis of these conditions is also emphasised, as a simple and effective treatment is available. Here we report clinical features, serological data and outcome of two recent cases of rickettsial diseases, tick typhus and an epidemic typhus in two Dutch travellers.

\section{Patient 1}

A 35-year-old veterinarian spent 27 days in South Africa. Before travelling he received immunoglobulin against hepatitis A virus infection, and reported to have been vaccinated against cholera and typhoid fever in South America in 1996. He took proguanil $^{\circledR}$ as chemoprophylaxis against malaria. On Sunday 12th October 1997, he returned home and while bathing he noticed a tick between two toes of his left foot. He removed the tick with a forceps and kept it in alcohol. Five days later he complained of a sudden fever, headaches fatigue and diffuse myalgia. Because the fever was persisting and a tender inguinal lymphadenopathy developed, the veterinarian suspected a possible vector borne disease, although he did not notice any rash or eschar. He called his family doctor and requested a prescription for doxycycline ${ }^{\circledR}$.

The general practitioner refused initially to prescribe the drug, but accepted only after the veterinarian insisted that the symptoms might have been caused by an infection with borrelia transmitted by the tick. After obtaining the desired drug the vet- erinarian doubted his motivation for the prescribed drug. A day later he started taking $200 \mathrm{mg}$ per day. Clinical improvement followed within 2 days. He did not remember when the fever subsided. The tick as well as two serum samples obtained 8 days and 30 days after his arrival were available for diagnostic purposes and sent to our laboratory. No other clinical and haematological data were available from this patient. In the acute stage no serological evidence of a rickettsial infection was detected. This could only be confirmed by the presence of IgM antibodies in the second sample, and a four fold $\mathrm{IgG}$ titre rise against Rickettsia conorii in the second sample measured by immunofluorescence test (IFT) as shown in Table 1. The presence of rickettsial DNA in the tissue of the collected tick supported the serological result [10].

\section{Patient 2}

A 41-year-old man, who travelled to India for 2 weeks, developed a headache, generalised myalgia, cold chills, nausea and vomiting during his flight back to The Netherlands. Upon return he was referred by his family doctor to our hospital on the 1st of December 1998 where he stayed for 2 weeks. On admission the body temperature was $41.0^{\circ} \mathrm{C}$, his blood pressure was $130 / 80 \mathrm{mmHg}$ and a heart rate of $92 \mathrm{bpm}$. Patient revealed that fleas or other insects in the hotel might have bitten him. None of his accompanying travellers $(n=6)$ showed any clinical symptoms. He did not take malaria chemoprophylaxis, as it was not advised for the places that he visited. Repeated physical examination did not reveal rash or lymphadenopathy. He had conjunctivitis and was not

Table 1

Detection of IgM and IgG antibodies against different rickettsiae species measured by IFT in two patients

\begin{tabular}{|c|c|c|c|c|c|}
\hline \multirow[t]{2}{*}{ Rickettsia species } & & \multicolumn{2}{|l|}{ Patient 1} & \multicolumn{2}{|l|}{ Patient 2} \\
\hline & & $\mathrm{S} 1(22 / 10)$ & $\mathrm{S} 2(20 / 11)$ & $\mathrm{S} 1$ (4/12) & $\mathrm{S} 2(15 / 12)$ \\
\hline \multirow[t]{2}{*}{ R. prowazekii } & $\operatorname{IgM}$ & $<16$ & $<16$ & $>512$ & $>4096$ \\
\hline & $\mathrm{IgG}$ & $<16$ & $<16$ & 128 & 1024 \\
\hline \multirow[t]{2}{*}{ R. conorii } & $\operatorname{IgM}$ & $<16$ & $>64$ & $<16$ & 256 \\
\hline & $\mathrm{IgG}$ & $<16$ & 512 & $<16$ & 256 \\
\hline \multirow[t]{2}{*}{ R. typhi } & $\operatorname{IgM}$ & $<16$ & $<16$ & 512 & $>4096$ \\
\hline & $\mathrm{IgG}$ & $<16$ & $<16$ & 32 & $>2048$ \\
\hline
\end{tabular}


icteric. Clinical examination of lungs, heart and central nervous system did not show abnormalities. Examination of the abdomen was normal except for the liver that was slightly enlarged. Laboratory examination showed a haemoglobin of $8.7 \mathrm{mmol} / \mathrm{l}$, a white blood cell count of $4.9 \times 10^{9} / 1$ with normal differential count, platelets of $121 \times 10^{9} / 1$ and erythrocyte sedimentation rate of $27 \mathrm{~mm} / \mathrm{h}$. Serum alanine aminotransferase (ALAT) level was $75 \mathrm{U} / 1$, serum aspartate aminotransferase (ASAT) of $52 \mathrm{U} / 1$, alkaline phosphate $57 \mathrm{U} / 1$, lactate dehydrogenases (LDH) $1109 \mathrm{U} / 1$, serum bilirubin $23 \mu \mathrm{mol} / 1$, gamma GT $50 \mathrm{U} / \mathrm{l}$, creatinine $105 \mu \mathrm{mol} / \mathrm{l}$. Urine cultures were negative and sediment contained albumin $(1+)$, leukocytes $(1+)$ and hemoglobin $(3+)$. On basis of the clinical symptoms the following differential diagnosis was considered: dengue fever, malaria and salmonellosis (typhi). Rickettsiosis was added to the differential diagnosis 4 days later. Blood culture on admission was negative, several times thick and thin blood films for malaria were found negative, and virus isolation procedures for dengue virus were negative. IgM serum antibodies against hepatitis A virus, hepatitis B virus, cytomegalovirus, Epstein Barr virus and dengue virus was negative. Serology for hepatitis $\mathrm{C}$ virus was also negative.

IFT carried out on serum samples collected on 4th and 15th of December 1998 for the demonstration of specific IgM and IgG against Rickettsia prowazekii were both positive confirming the diagnosis of primary epidemic typhus infection. Doxycycline treatment at $200 \mathrm{mg}$ a day was given for 1 week. The fever subsided and clinical improvement followed slowly. While still weak the patient was discharged from the hospital on 16th of December 1998. Serological results of these two cases are summarised in Table 1.

\section{Discussion}

A simple and effective treatment for rickettsioses has long been established. Rickettsial diseases should be considered in febrile patients with a negative blood smear examination for malaria returning from endemic area [11]. The typical clinical presentation are characterised by fever, headache and rash. Positive serology can be expected between 5- 10 days after onset of illness. The use of PCR techniques can overcome the problems with serology in the acute phase allowing earlier diagnosis during the acute stage of the disease by detection of rickettsial DNA in blood samples and skin biopsy or arthropod tissues. Our aim in reporting these two cases is to emphasise and stress the benefits of an early diagnosis of these infections. The difference between the two patients was the time point at which the empirical treatment for rickettsioses was established after infection. Better awareness of the possibility of a vector borne diseases, though suggested by the presence of the tick, has led in the first patient to be empirically treated on clinical suspicion before serological evidence. Serological tests confirmed the diagnosis of boutonneuse fever in the first patient by showing seroconversion to antibodies against $R$. conorii and by PCR analysis of the tick. Immediate clinical improvement and disappearance of fever followed early initiation of proper treatment within 2 days with minimal economic loss. In contrast, unawareness of the possibility of a rickettsial infection in the second patient resulted in severe disease and the need for a prolonged hospitalisation. In serum samples from the second patient, high titres of both IgM and IgG antibodies against $R$. prowazekii and $R$. typhi were detected with IFT, indicating an infection with a rickettsia species from the typhi group, although on epidemiological grounds it is much more likely that the patient may had suffered from a flea-borne typhus.

The apparent difference in the costs associated by treating these two patients was related only to the time the empirical treatment was started and the serological diagnosis was considered. We conclude that failure of an early diagnosis and omission of specific antibiotic therapy for Rickettsia infections may have far-reaching clinical and costly consequences.

Recommendation: awareness should be increased among family doctors and medical specialists about the possibility of rickettsioses when evaluating their patients suffering from fever after travelling to disease endemic areas of the world since these infections can be treated effectively when diagnosed early.

- Rickettsioses should be considered among febrile 
patients returning from endemic areas with a negative blood smear for malaria

- The main symptoms of Rickettsioses are fever, headache and rash

- The major forms are spotted fever group (e.g. Rickettsia conorii), typhus group (R. typhii and $R$. prowazekii), ehrlichiosis group and others like $\mathrm{Q}$ fever (coxiella Burnetii)

- The geographical distribution of Rickettsial diseases is associated with the distribution of its arthropod host (ticks, mites, lice and fleas)

- There is considerable serological cross-reactivity between Rickettsial species.

\section{References}

[1] Raoult D, Roux V. Rickettsioses as paradigms of new emerging infectious diseases. Clin. Microbiol Rev 1997;4:694-719.

[2] Thiebaut MM, Bricaire F, Raoult D. Scrub typhus after a trip to Vietnam. New Engl J Med 1997;336:1613-4.

[3] Marschang A, Nothdurft HD, Kumlien S, von Sonnenburg F. Imported rickettsioses in German travellers. Infection 1995;23:94-7.
[4] Jensenius M, Gerlyng P, Hasle G, Hopen G, Vene S, Bruu AL. Spotted fever imported into Norway in 1997. Tijsskr Nor Laegeforen 1998;118:2627-9.

[5] Dupon M, Rogues AM, Malou M, d'Ivernois C, Lacut JY. Scrub typhus: An imported rickettsial disease. Infection 1992;20:153-4.

[6] Reep-van den Bergh CM, Docters van Leeuwen WM, van Kessel RP, Lelijveld JL. Malaria: under-notification and risk assessment for travellers to the tropics. Ned Tijdschr Geneeskd 1996;140:878-82.

[7] Duval X, Chosidow O, Tissot-Dupont H, Raoult D, Frances C. Cutaneous signs of Rickettsia and related microorganisms. Rev Med Interne 1998;19:548-57.

[8] Groen J, Nur YA, Dolmans W, Ligthelm RJ, E Osterhaus ADM. Scrub and murine typhus among Dutch travellers. Infection 1999;27:291-2.

[9] Ruys TA, Schrijver R, Van't Wout JW. Boutonneuse fever caught in The Netherlands: A travelling dog as source of Rickettsia conorii. Ned Tijdschr Geneeskd 1994;138:2592-4.

[10] Williams JW, Radulovic S, Dash GA, Lindstrom J, Kelly DJ, Oster CN, Walker DH. Identification of Rickettsia conorii infection by polymerase chain reaction in a soldier returning from Somalia. Clin Infec Dis 1994;19:93-9.

[11] Kager PA. Virale hemorragische koorts. Ned Tijdschr Geneeskd 1998;142:448-52. 